5 University Student Engagement Inventory (USEI): Psychometric properties

7 Jorge Sinval ${ }^{1}$, Joana R. Casanova ${ }^{2}$, João Marôco ${ }^{1}$, \& Leandro S. Almeida ${ }^{2}$

1 William James Center for Research, ISPA - Instituto Universitário

2 Research Centre in Education (CIEd), Institute of Education, University of Minho

10

11

12

13

Acknowledgments

Jorge Sinval received funding from the William James Center for Research, Portuguese Science Foundation (FCT UID/PSI/04810

12013). Leandro S. Almeida and Joana R. Casanova received funding from CIEd - Research Centre on Education, projects

UID/CED/1661/2013 and UID/CED/1661/2016, Institute of Education, University of Minho, through national funds of FCT/MCTES-PT.

23 The final publication is available at link.springer.com (http://dx.doi.org/10.1007/s12144-

$24 \quad \underline{018-0082-6})$. 


\section{University Student Engagement Inventory (USEI): Psychometric properties}

\section{Abstract}

28 Academic engagement describes students' investment in academic learning and achievement

29 and is an important indicator of students' adjustment to university life, particularly in the first

30 year. A tridimensional conceptualization of academic engagement has been accepted

31 (behavioral, emotional and cognitive dimensions). This paper tests the dimensionality,

32 internal consistency reliability and invariance of the University Student Engagement

33 Inventory (USEI) taking into consideration both gender and the scientific area of graduation.

34 A sample of 908 Portuguese first-year university students was considered. Good evidence of

35 reliability has been obtained with ordinal alpha and omega values. Confirmatory factor

36 analysis substantiates the theoretical dimensionality proposed (second-order latent factor),

37 internal consistency reliability evidence indicates good values and the results suggest

38 measurement invariance across gender and the area of graduation. The present study

39 enhances the role of the USEI regarding the lack of consensus on the dimensionality and

40 constructs delimitation of academic engagement.

41 Keywords: academic engagement, higher education, first-year students, assessment, 42 measurement invariance 


\section{Introduction}

Research on engagement emerged from professional and occupational contexts. In these contexts, engagement is defined as a positive psychological state that is characterized by vigor, dedication and absorption associated with work-related well-being (Bakker et al. 2008; Hirschi 2012; Schaufeli and Bakker 2010). In recent years engagement has also been studied in educational contexts, namely in higher education (Bresó et al. 2011; Christenson and Reschly 2010; Kuh 2009; Vasalampi et al. 2009). These studies are often present in international research concerning academic learning and achievement (Krause and Coates 2008; Schaufeli, Martinez, Marques Pinto, et al. 2002).

Students' academic engagement can be defined as the time, intention and energy students devote to educationally sound activities. Academic engagement is related to the policies and practices that institutions use to induce students to take part in those activities (Hodson and Thomas 2003; Kuh 2005; Wierstra et al. 2003). Research has established that engaged students invest more in their performance, participate more and tend to develop mechanisms to help them persist and self-regulate their learning and achievement (Klem and Connell 2004; National Research Council and Institute of Medicine 2004).

Academic engagement is associated with a positive way of experiencing academic activities and contexts, since it is related to positive academic and social outcomes (Klem and Connell 2004; Wonglorsaichon et al. 2014), to satisfaction and self-efficacy (Coetzee and Oosthuizen 2012), and to a reduction of achievement problems, burnout and dropout (Chapman et al. 2011; Christenson et al. 2012; Christenson and Reschly 2010; Eccles and

Wang 2012; Elmore and Huebner 2010; Finn and Zimmer 2012; Fredricks et al. 2004, 2011;

65 Gilardi and Guglielmetti 2011; Reschly and Christenson 2012a). 
As engagement is a broad meta-construct it can be problematic because various

67 definitions exist both within and across the different types of engagement (Fredricks et al.

68 2016). Two dominant conceptualizations of academic engagement have emerged in the

69 literature (for a recent debate on academic engagement see Senior and Howard 2015).

70 Schaufeli, Martinez, Marques-Pinto, Salanova and Bakker (2002) adapted the Utrecht Work

71 Engagement Scale (UWES) from the business organizations' perspective to measure student

72 engagement in university settings. The adapted scale, the UWES - Student version (UWES-

73 S), uses the same three work engagement dimensions (vigor, absorption and dedication)

74 adapted to the university context by rephrasing some of the original UWES items. The other

75 predominant student academic engagement conceptualization by Fredricks et al. (2004)

76 defines academic engagement as a multidimensional construct, integrating behavioral,

77 emotional and cognitive dimensions, which is usually in line with the notion that the

78 behavioral component corresponds to vigor, the emotional one to dedication and the

79 cognitive one to absorption (Christensen 2017). However, criticisms have been raised

80 regarding Salanova et al.'s (2002) and Fredricks et al.'s (2004) student academic engagement

81 conceptualizations. The former was a simple adaptation of the workplace to the university

82 context; the latter was derived mainly for high school students (Marôco et al.

83 2016).Theorizing academic engagement as a multidimensional construct allows for the better

84 generalization and understanding of academic engagement as a combination of its several

85 factors. Also, analysis of the engagement first-order factors (behavioral, emotional and

86 cognitive) allows for pinpointing the different contribution to overall engagement and direct

87 interventions.

88 Clarification is needed since some theoretical frameworks almost overlap with 89 previous literature (Fredricks 2015). In the academic engagement literature, there is a need 
90 for clear definitions with differentiation between the dimensions within the adopted

91 framework (Fredricks et al. 2004). Raising the importance of having measures that take this

92 into consideration without crossing the content of different dimensions of different factors

93 increases the utility of analyzing the validity evidence of multidimensional psychometric

94 instruments. Marôco, Marôco, Campos and Fredricks (2016) reviewed the main criticisms of

95 both approaches and developed the University Student Engagement Inventory (USEI). This

96 inventory includes the behavioral, cognitive and emotional dimensions of academic

97 engagement, which is the definition and division of dimensions adopted by most research

98 (Fredricks 2015). The behavioral dimension is related to behaviors such as attending classes,

99 arriving on time, doing prescribed tasks/homework in scheduled time, participating in

100 activities in and out of the classroom, and respecting the social and institutional rules. The

101 cognitive dimension refers to all the students' thoughts, perceptions and strategies related

102 with the acquisition of knowledge or development of competencies to academic activities,

103 for example their study methods, learning approaches and academic self-regulation. The

104 emotional dimension refers to positive and negative feelings and emotions related to the

105 learning process, class activities, peers and teachers, for example a sense of belonging,

106 enthusiasm, and motivation (Antúnez et al. 2017; Carter et al. 2012; Marôco et al. 2016;

107 Sheppard 2011). Validity evidence based on response processes (i.e. face validity) of the

108 behavioral, cognitive and emotional as dimensions of academic engagement was evaluated

109 by a focus group of university students and psychologists in the original proposal of Mâroco

110 et al. (2016). In this study, we focus on the validity evidence based on the USEI's internal

111 structure.

112 Although there is a consensus about the relevance of this construct to the explanation

113 of academic behavior and learning, there is not a precise delimitation of the construct and its 
114 dimensionality (Christenson et al. 2012; Fredricks and McColskey 2012; Kahu 2013;

115 Reschly and Christenson 2012; Wolf-Wendel et al. 2009). A debate is still ongoing

116 concerning the definition and internal structure of the academic engagement construct. This

117 conceptual haziness (Appleton et al. 2008) extends to the dimensionality of the construct's

118 instruments: Some authors assume it to be a unidimensional primary factor or a second-order

119 factor as it is a general motivational trait or state, while other authors defend its

120 multidimensionality, but without consensus regarding the number of dimensions (Fredricks

121 et al. 2004; Handelsman et al. 2005; Lin and Huang 2018; Reschly and Christenson 2012b).

122 In this paper, we focus on the USEI for the university context and evaluate one of the 123 sources of evidence proposed in the Standards for Educational and Psychological Testing

124 (American Educational Research Association et al. 2014) regarding the validity evidence 125 based on the internal structure. Specifically, we aim to find good validity evidence regarding 126 the dimensionality of the first-order three-factor model (H1) of a possible second-order latent

127 factor model (H2), measurement invariance for gender (H3) and for the scientific area of 128 college graduation (H4), and good evidence of reliability of the scores through internal 129 consistency using several estimates (H5). This type of validity indicators intends to 130 demonstrate the relevance of an instrument that simultaneously can be useful to investigation 131 and practice. Namely, shown evidence of a meta-construct (academic engagement) which is 132 useful for research, demonstrating the utility of its specific domains for interventions with 133 specific students' subgroups.

\section{Method}

136 Validity is a vital issue when it refers to the quality of psychometric scales, and it 137 refers to the extent to which the evidence supports the interpretation of scale scores (Crutzen 
138 and Peters 2017). Validity concerns the understanding of scale scores in a specific study; it

139 isn't a characteristic of a scale in itself (American Educational Research Association et al.

140 2014). Consequently, evidence from other studies must be used to justify the choice of a

141 specific scale, although in a strict sense it doesn't guarantee the same validity evidence in a

142 new study (Crutzen and Peters 2017). Nevertheless, every study that uses psychometric

143 scales must pay attention to the validity evidence brought by each scale in each study.

144 Historically, different types of validity have been approached; the current Standards for

145 Educational and Psychological Testing evolved after the first version, more than 60 years

146 ago (American Psychological Association 1954). The current Standards approach validity as

147 a unitary concept, with five sources of validity recognized (Sireci and Padilla 2014): based

148 on internal structure, based on test content, based on the relation to other variables, based on

149 response processes and based on the consequences of testing. Although these are not

150 considered to present distinct types of validity, an inclusive evaluation of the instrument

151 includes these different sources of evidence in a coherent account (American Educational

152 Research Association et al. 2014).

153 Validity evidence based on the internal structure includes three basic aspects:

154 dimensionality, measurement invariance and reliability (Rios and Wells 2014). To assess

155 dimensionality, one can opt for several factor analytic methods; however, confirmatory factor

156 analysis (Brown 2015) is the most comprehensive approach for comparing observed and

157 hypothesized test structures, as it evaluates the relationships between items and the latent

158 variables (theoretical constructs) and which items should be measured (Bollen 1989).

159 Measurement invariance assesses whether an instrument is fair for different

160 subgroups from a psychometric perspective (van de Schoot et al. 2012), such as occupations

161 (Sinval et al. 2018), countries (Reis et al. 2015), genders (Marsh et al. 2010) and other groups. 
162 It can also be evaluated using different statistical approaches, with multigroup confirmatory

163 factor analysis being the most popular (Davidov et al. 2014). This approach consists of setting

164 increasingly constrained sets of structural equation models, and comparing the more

165 restricted models with the less restricted models (van de Schoot et al. 2015).

166 Since the validity of scores depends on their reliability (American Educational

167 Research Association et al. 2014), without reliability we can't have appropriate validity

168 evidence (Kaplan and Saccuzzo 2013). It can be evaluated with different techniques,

169 although the most usual is through internal consistency estimates, such as Cronbach's $\alpha$,

170 Revelle's $\beta$ or McDonald's $\omega_{\mathrm{h}}$ (Zinbarg et al. 2005). It provides evidence about the

171 consistency of the test scores across repeated administrations (American Educational

172 Research Association et al. 2014).

173

\section{Participants}

175 A sample of 908 Portuguese first-year university students (ages ranging from 17 to

17658 years; $M=19.41 ; S D=4.79 ; M d n=18$ ) from a public university in the north of Portugal

177 was used to evaluate the psychometric properties of the USEI. These students commonly

178 took courses in three main areas: $40.18 \%$ were from technology or engineering courses;

$17929.52 \%$ from economics or law courses; and 30.30\% from languages or humanities. Most

180 students were women (64.58\%) and only 8.57\% had a part-time or full-time occupation. With

181 respect to parents' level of education, $50.65 \%$ of mothers had a basic education level, $30.27 \%$

182 a high school level and $19.08 \%$ a higher education level; meanwhile, $58.99 \%$ of fathers had

183 a basic education level, 24.64\% had a secondary level and 16.38\% a higher education level. 


\section{Measures and procedures}

The USEI (Marôco et al. 2016) is a self-report Likert-type $(1=$ "never" to $5=$

187 “always") scale with 15 items organized in three academic engagement dimensions:

188 behavioral (BE; e.g. I usually participate actively in group assignments), cognitive (CE; e.g.

189 I like being at school) and emotional (EE; e.g. I try to integrate the acquired knowledge in

190 solving new problems). This instrument presented good evidence of reliability and factorial,

191 convergent and discriminant validity evidence in a previous research study (Marôco et al.

192 2016). Exploratory and confirmatory factor analyses confirm systematically specific items

193 for each dimension. Reliability coefficients in terms of the consistency of items are above .63

194 (ordinal omega values) and above .69 (ordinal alpha values) for three dimensions.

195 A non-probabilistic convenience sample was considered, with the inclusion criterion

196 being students entering university. Data were collected in the classroom context with the

197 permission and collaboration of teachers. The aims of the study were presented, and

198 confidentiality was ensured. The participants provided informed consent stating their

199 voluntary agreement to participate in the study. Ten minutes were enough to fill in the

200 inventory and give some personal information for sample characterization.

202 Data analysis

203 All statistical analysis was performed with R (R Core Team 2018) and RStudio

204 (RStudio Team 2017). The descriptive statistics were obtained using the skimr package

205 (Rubia et al. 2017). Confirmatory factor analysis (CFA) was conducted to evaluate the

206 psychometric properties of the data gathered with the USEI, namely its internal structure

207 validity evidence. CFA was performed with the lavaan package (Rosseel 2012) using the 
208 weighted least squares means and variances (WLSMV) estimation method, which is

209 indicated for nonlinear response scales. Internal consistency reliability estimates for ordinal

210 variables, average variance extracted (AVE) and heterotrait-monotrait (HTMT) were

211 calculated using the semTools package (semTools Contributors 2016), while Mardia's

212 Kurtosis (Mardia 1970) was assessed using the psych package (Revelle 2017).

213 The CFA was conducted to verify whether the proposed three-factor structure presented

214 an adequate fit for the study sample data. We used as goodness-of-fit indices the TLI (Tucker-

215 Lewis Index), $\chi^{2 /} \mathrm{df}$ (ratio of chi-square to degrees of freedom), the NFI (Normed Fit Index),

216 the CFI (Comparative Fit Index) and the RMSEA (Root Mean Square Error of

217 Approximation). The fit of the model was considered good for CFI, NFI and TLI values

218 above .95 and RMSEA values below .06 (Hu and Bentler 1999; Marôco 2014).

219 To analyze convergent validity evidence, the AVE was estimated as described in Fornell

220 and Larcker (1981). Values of $A V E \geq .5$ were considered acceptable indicators of convergent

221 validity evidence. To determine whether the items that are manifestations of a factor were

222 not strongly correlated with other factors, discriminant validity evidence was assessed.

223 Acceptable discriminant validity evidence was assumed when for two factors $x$ and $y, A V E_{x}$

224 and $A V E_{y} \geq \rho^{2} x y$ (squared correlation between the factors $x$ and $y$ ), or when the HTMT

225 (Henseler et al. 2015) ratio of correlations is higher than .85 (Kline 2016).

226 The reliability of the internal scores evidence was assessed through internal consistency

227 measures. The ordinal Cronbach's alpha coefficient $(\alpha)$ and composite reliability (CR) were

228 calculated. Since alpha has been shown to present evidence of a measure's internal

229 consistency only when the assumptions of the essentially tau-equivalent model are obtained

230 (Revelle and Zinbarg 2009), the ordinal coefficient omega ( $\omega)$ for each factor (Raykov 2001; 
231 Zumbo et al. 2007) and the hierarchical omega $(\omega \mathrm{h})$ coefficient (Green and Yang 2009; Kelley 232 and Pornprasertmanit 2016; McDonald 1999) were also calculated. Higher alpha values are

233 desirable, although excessively high values of alpha aren't recommended, as this reveals 234 unnecessary repetition and overlap (Streiner 2003). Values of $C R \geq .7$ were considered to be 235 satisfactory indicators of internal consistency (Marôco 2014). Omega values show evidence 236 of how much of the overall variance of a factor in the data that is due to that specific factor, $237 \omega$, was calculated for each of the three factors. As regards the $\omega \mathrm{h}$, a higher value will indicate 238 a stronger influence of the latent variable common to all of the factors, and that the observed 239 scale scores generalize to scores for the common latent variable (Zinbarg et al. 2007). The 240 second-order factor reliability was also calculated using the omega coefficient (Jorgensen et 241 al. 2018).

The measurement invariance of the second-order model was assessed with the lavaan 243 package (Rosseel 2012), and we established a set of comparisons within a group of seven 244 different models based on the recommendations for ordinal variables (Millsap and Yun-Tein 245 2004) and for second-order models (Chen et al. 2005). An initial configural model was set, 246 which served as a baseline (configural invariance) for further equivalence testing (Edwards 247 et al. 2017). Next, metric invariance of the first-order factor loadings was tested with the 248 items' loadings forced to be equal across groups; this assessed whether the subgroups 249 attribute the same meaning to the different instrument items. The next step consisted in 250 forcing the second-order factor loadings to be equal across groups; this checked whether the 251 subgroups give the same meaning to the factors that compose the second-order latent factor.

252 Afterwards, scalar invariance of the first-order factors was tested, where thresholds were 253 added to be equal across groups (Millsap and Yun-Tein 2004). If scalar invariance was 
254 obtained, it meant that the means or the thresholds of the items are also equal across the 255 subgroups, enabling comparisons between the different subgroups. Next, scalar invariance

256 of the second-order latent factor was tested, where the intercepts of the first-order latent

257 variables were forced to be equal across groups. This checked whether the first-order latent

258 levels were equal across groups. Usually, this was enough for measurement invariance, since

259 the next levels are too restrictive (Marôco 2014). After, the disturbances of first-order factors

260 were established as being equal across groups, to verify if the explained variances for the

261 first-order latent factors were equal across groups. Finally, if residual variances were also

262 added to be equal across groups without statistically significant differences, full uniqueness

263 measurement invariance was obtained, which means that the explained variance for all items

264 didn't change in regard to the subgroup (van de Schoot et al. 2012). Invariance across the

265 different levels can be assessed using two different criteria: the $\Delta$ CFI $<.01$ between

266 constrained and free models(Cheung and Rensvold 2002), and the $\Delta \chi^{2}$ test comparing the fit

267 of the constrained vs. free models is not statistically significant (Satorra and Bentler 2001).

269 Results

$270 \quad$ Items'distributional properties

271 Summary measures, skewness $(s k)$, kurtosis $(k u)$ and a histogram for each of the 15

272 items are presented (Table 1) and were used to judge distributional properties and

273 psychometric sensitivity. Absolute values of $k u$ smaller than 7 and $s k$ smaller than 3 were

274 considered an indication of not strong deviations from the normal distribution (Finney and

275 DiStefano 2013). Mardia's multivariate kurtosis for the 15 items of the USEI was $37.5 ; p$

$276<.001$. All possible answer values for each item are also present, and no outliers were deleted. 
277 Also interesting is the reduced number of missing answers from the 15 items (11 omissions

278 from item 10 "My classroom is an interesting place to be").

The items' distributional coefficients are indicative of appropriate psychometric

280 sensitivity, as it would be expected that these items would follow an approximately normal

281 distribution in the population under study. Despite these univariate and multivariate

282 normality indicators, the WLSMV estimator was used to account for the ordinal level of

283 measurement of the items, which can be done without concerns about this estimate.

Insert Table 1

\section{Factorial validity evidence}

In light of the previous researches on the USEI structure confirming the existence of

291 three dimensions, a confirmatory factor analysis was performed. The hypothesized three-

292 factor model's fit with the data was good (Figure 1; correlations between latent variables, and

293 factor loadings for each item are shown), since CFI, NFI and TLI values were greater

294 than .95, and RMSEA values were less than .06. It is also important that the factor loadings

295 of all items are greater than .50, except for item 6 (the only reversed coded item in the

296 instrument).

297 Figure 1 - Confirmatory factor analysis of the University Students Engagement Inventory 298 (15 items) with first-year Portuguese university students $\left(\chi^{2}(87)=286.665, p<.001, n=\right.$ $299871, C F I=.987, T L I=.985, N F I=.982, R M S E A=.051, P($ RMSEA $\leq .05)=.356$, IC90 $300 \quad$ ].045; .058[. R - Reversed. 
The average variance extracted (AVE) was acceptable for EE (.54), nearly acceptable for $\mathrm{CE}(.49)$ and low for BE (.31). The convergent validity evidence was acceptable for the

$310 \mathrm{CE}$ and $\mathrm{EE}$ factors and unsatisfactory for the BE factor.

\section{Discriminant validity evidence}

313 Comparing data from these three dimensions, the AVE for $\mathrm{EE}\left(A V E_{\mathrm{EE}}=.54\right)$ was greater

314 than $r^{2} \mathrm{BE} . \mathrm{EE}(.36)$, but the $A V E_{\mathrm{BE}}=.31$ was lower, the $A V E_{\mathrm{CE}}=.49$ and $A V E_{\mathrm{EE}}=.54$ were both 315 greater than $r^{2}{ }_{\mathrm{EE} . \mathrm{CE}}=.24$, and the $A V E_{\mathrm{BE}}=.31$ and $A V E_{\mathrm{CE}}=.49$ were both less than $r^{2}{ }_{\mathrm{BE} . \mathrm{CE}}$

$316=.52$. The discriminant validity evidence was good for $\mathrm{CE}$ and $\mathrm{EE}$, insufficient for $\mathrm{BE}$ and

$317 \mathrm{EE}$, and poor for BE and CE. With regard to the HTMT criterion, the HTMTBE.EE $=.60$, $318 \mathrm{HTMT}_{\mathrm{BE} . \mathrm{CE}}=.73$ and $\mathrm{HTMT}_{\mathrm{EE} . \mathrm{CE}}=.51$, with all being below the recommended threshold.

319 Together, these findings detect strong correlations/overlap among the three latent constructs.

320 This points to a possible higher-order latent factor.

322 Second-order construct

323 We tested the possible existence of a higher-order latent variable, the meta-construct

324 academic engagement, which was hypothesized by the original authors (Marôco et al. 2016), 325 and suggested also by our lack of discriminant validity evidence findings. In regard to the 326 USEI with a second-order latent factor, overall the goodness-of-fit indices were good (Figure 327 2; gamma between the second-order latent factor and the first-order latent factors, and factor 328 loadings for each item are shown). The structural weights for the academic engagement 
329 second-order factor model were medium/high: behavioral engagement $(\gamma=0.93 ; p<.001)$;

330 emotional engagement $(\gamma=0.64 ; p<.001)$; and cognitive engagement $(\gamma=0.77 ; p<.001)$.

331 Figure 2 - Confirmatory factor analysis of the University Students Engagement Inventory

332 (second-order model -15 items) with first-year Portuguese university students $\left(\chi^{2}(87)=\right.$

$333286.665, p<.001, n=871, C F I=.987, T L I=.985, N F I=.982, R M S E A=.051, P(\mathrm{RMSEA}$

$334 \leq .05)=.356$, IC90 ].045; .058[. R - Reversed.

335

336

337

338

339

340

341

Reliability: Internal consistency evidence

In terms of the hypothesized reliability evidence, the results suggest good evidence of

343 internal consistency reliability (Table 2). The alpha values were higher than the omega values

344 for all factors and for the total scale. The hierarchical omega for the total scale was good $\left(\omega_{\mathrm{h}}\right.$

$345=.85)$, which suggests a well-defined latent variable, thereby evidencing that this latent

346 variable is more likely to be stable across studies, which also suggests that the general factor

347 academic engagement is the dominant source of systematic variance (Rodriguez et al. 2016).

Insert Table 2

The internal consistency reliability of the second-order latent variable was good. The

352 proportion of observed variance explained by the second-order factor after controlling for the

353 uniqueness of the first-order factor ( $\left.\omega_{\text {partial L1 }}\right)$ was .87 , the proportion of the second-order

354 factor explaining the variance of the first-order factor level ( $\left.\omega_{\mathrm{L} 2}\right)$ was .87 and the proportion

355 of the second-order factor explaining the total score ( $\omega \mathrm{L} 1)$ was .72. 
Measurement invariance by gender and scientific area of graduation

Finally, to detect whether the same second-order latent model holds in different

359 scientific areas of graduation and genders, a group of nested models with indications of

360 equivalence is needed. The hypothesized full-scale invariance was supported for gender

361 (Table 3) using the Cheung and Rensvold (2002) $\Delta$ CFI criterion, while the $\Delta \chi^{2}$ criterion

362 supported only the second-order metric invariance. In regard to the hypothesized structural

363 invariance among different areas of study, full-scale invariance was supported by the $\Delta \mathrm{CFI}$

364 criterion, nevertheless the $\triangle \mathrm{CFI}$ value for the first comparison was marginal at .010, although

365 the $\Delta \chi^{2}$ supported it, after we continued with the comparisons; the $\Delta \chi^{2}$ criterion allowed only

366 the first-order metric invariance (see Table 4). In both cases, the $\triangle$ CFI criterion was

367 preferable, since the $\Delta \chi^{2}$ is too restrictive (Marôco 2014).

368

369

370

371

372

373

374

375

376

377

378

379

380

381
Insert Table 3

Insert Table 4

\section{Discussion}

\section{Hypotheses findings}

This study obtained findings that allow our $\mathrm{H} 1$ to be confirmed, since the data gathered with the USEI presented good psychometric properties in terms of validity evidence based on the internal structure, something that was observed in other studies with this instrument, which obtained acceptable/good overall goodness of fit (Costa et al. 2014) and 
382 good overall goodness of fit (Marôco et al. 2016). The confirmatory factor analysis presented

383 good evidence about factorial validity, since goodness-of-fit indices values ranged from very

384 good to good, and only item 6 had a lambda of less than .50. Analyzing its content, item 6 is

385 the only one reverse coded, which suggests that it should be presented in the same direction

386 as the other items in the future. Marôco, Marôco and Campos (2014) report this kind of

387 improvement in the items' correlations in student burnout (an opposite construct to academic

388 engagement). The USEI's convergent validity evidence is acceptable and the AVE values

389 were good for the EE dimension, marginally acceptable for CE and less than acceptable for

390 BE. These values show that the items of each dimension were good manifestations of the

391 factors they load onto. The discriminant validity evidence of the instrument was acceptable

392 for two of the three factors. The lack of discriminant validity evidence for BE may be due to

393 our sample being composed only of freshmen; in the original USEI study (Marôco et al.

394 2016) with students from other academic years, this lack of discriminant validity evidence

395 was not observed.

396 Our H2 was confirmed, something that has been tested by the original authors, with

397 whom our results were aligned in terms of structural weights, with behavioral engagement

398 having the highest gamma, followed by cognitive engagement and finally emotional

399 engagement (Marôco et al. 2016).

400 With regard to $\mathrm{H} 3$ and $\mathrm{H} 4$, our results brought evidence that allows comparisons to

401 be established between male and female genders using the USEI, and between first-year 402 students from technology or engineering courses, from economics or law courses, and from 403 languages or humanities. This finding was a novelty of our study, and is useful since previous 404 studies only assessed engineering students (Costa et al. 2014; Costa and Marôco 2017) or 405 even with a sample from different courses - didn't test measurement invariance for the 
406 scientific area of graduation (Marôco et al. 2016). Another novelty of this study was the test

407 of the second-order measurement invariance, since the only study that has tested

408 measurement invariance using this instrument (Marôco et al. 2016) did so only to compare

409 the structure between two independent samples without comparing specific scientific areas

410 of graduation, and regarding the first-order model. This finding will enable future

411 comparisons among these different groups to verify possible differences and their impact on

412 academic adjustment and achievement.

413 With regard to the evidence obtained about reliability, it was good for CR, ordinal $\alpha$,

414 ordinal $\omega$ and $\omega_{\mathrm{h}}$, suggesting adequate reliability of the data measured with the USEI. Our

415 results confirm our $\mathrm{H} 5$, and - nevertheless - are aligned with what was found in other studies,

416 where BE obtained lower reliability estimates than EE and CE (Costa et al. 2014; Marôco et

417 al. 2016).

418 Academic engagement is a relevant construct for describing student adaptation and

419 achievement in higher education. Engaged students tend to invest more in their performance

420 and develop strategies to persist in and to self-regulate their learning (Christenson and

421 Reschly 2010; D1lekmen 2007; Fredricks et al. 2011; Klem and Connell 2004). Consequently,

422 better academic success is expected (Lee 2014). In the literature, some consensus exists

423 defining academic engagement as a multidimensional construct, integrating behavioral, 424 emotional and cognitive dimensions (Fredricks et al. 2004). Our data from the USEI confirm 425 these three dimensions for describing students' academic engagement. Albite the second426 order construct (academic engagement) presents higher path loadings in the behavioral 427 dimension $(\gamma=.93)$ than emotional and cognitive engagement, respectively $\gamma=.64$ and $\gamma$ $428=.77$. The differences are pertinent and are in line with the expected, since our sample was 429 constituted by freshmen. The literature suggests that the first-years students have less 
maturity and autonomy to cope with the challenges of higher education (Bernardo et al. 2017;

431 Pascarella and Terenzini 2005). The first-year college students have their academic 432 engagement more expressed on behavioral terms, which can be seen on the academic routines 433 and tasks (e.g. attend to classes, group assignments).

434 Based on the foregoing discussion, we conclude that the USEI presents good validity 435 evidence about its internal structure, presenting promising results for future studies related to 436 other sources of validity and different university students' samples. This instrument can 437 become an interesting tool for education and psychology researchers for analyzing the 438 relationship between the different types of academic engagement and other personal and 439 academic variables important for students' adjustment and academic achievement.

440 Although domain-specific subject areas aren't included in the instrument, they may 441 contribute to understanding the extent to which engagement is content-specific, and to what 442 extent it represents a general engagement tendency (Fredricks et al. 2004). Since this was a 443 study carried out with a sample of university students from different courses, it wasn't 444 desirable to have a different version for each course, and it wasn't practical either because of 445 time and resource constraints. If one wants to understand and study a specific academic 446 engagement dimension, this kind of more inclusive instrument might be insufficient, 447 although if the goal of the study is to obtain a single measure for each of the three types of 448 academic engagement, this instrument may be a good choice, since it addresses each 449 construct with few items, and the last word is given to the researcher.

\section{Theoretical Implications}

452 This study presents some theoretical findings that can enable a better understanding 453 of academic engagement as a multidimensional construct. USEI revealed a three-factor 
454 structure that appears to be indicative of a higher-order construct, academic engagement. This

455 makes USEI unique regarding the potential of its conceptualization of academic engagement

456 as a meta-construct (Fredricks and McColskey 2012b), which is important to define well in

457 terms of its subdimensions (Fredricks et al. 2016). The results emphasize that this conception

458 of academic engagement works well in different scientific areas of college graduation

459 courses. There are some other subject specific instruments (Kong et al. 2003; Wigfield et al.

460 2008), but USEI has the particularity of being a general measure of academic engagement

461 for university students.

462 This is the first report addressing the USEI validity for students majoring different

463 study areas. The behavioral and emotional components of academic engagement in this

464 instrument didn't present the desired discriminant validity evidence, appearing to be

465 somehow related to their content. Our validity evidence supports a consistent alignment with

466 the academic engagement construct definition, showing good psychometric properties for the

467 study sample. As a convergence or product of motivation and active learning behaviors,

468 academic engagement works as a relevant variable with a strong impact in predicting the

469 student's permanence and success in completing his or her course in higher education 470 (Alrashidi et al. 2016; Barkley 2010; Kuh 2001).

\section{Practical Implications}

As for practical implications, USEI can be considered a tool with good psychometric

474 properties that can measure the perceptions of academic engagement behaviors, emotions 475 and internal cognitions in first-year university students. It is an instrument that was 476 specifically designed for university students and it is available for free. This can be done 477 across groups of different scientific areas of graduation and genders, without losing the 
478 desirable measurement invariance that enables direct comparisons of scores between those

479 groups. This is something that hasn't been done before across gender or the scientific area of 480 graduation. These findings together can bring confidence to the measures obtained using the 481 USEI, knowing the academic engagement predictive relation with other variables. For 482 example, Costa and Marôco (2017) found that the emotional subdimension of academic 483 engagement had a statistically significant relation with students' dropout thoughts. 484 Consequently, this is an important implication, since USEI can be useful to assess 485 interventions for specific dimensions of students' engagement. USEI is particularly useful 486 for measuring cognitive engagement and emotional engagement, that are not directly 487 observed (Fredricks and McColskey 2012b). With USEI these subdimensions don't need to 488 be inferred from behavioral indicators or teacher rating scales, avoiding potential inferences 489 through those other methods (Appleton et al. 2006).

490 Self-report instruments have several advantages over other methods, they are 491 practical and relatively low cost tools for group or large-scale assessments (Mandernach 492 2015). This allows to obtain data over several waves and establish different types of 493 comparisons (e.g. universities, courses). The large-scale assessment of academic engagement 494 enables teachers, policymakers and administrative boards to assess students' learning status 495 and their academic life experiences (Coates 2005), making it possible to obtain relevant 496 instructional feedback to the institution's decision-makers and to the students themselves 497 regarding the measured constructs (Banta et al. 2009; Kember and Leung 2009). In this sense, 498 due to its psychological, contextual nature and complexity, academic engagement assessment 499 should take a multidimensional approach considering the behavioral, emotional and 500 cognitive aspects (Alrashidi et al. 2016; Mandernach 2015). This multidimensional approach 501 allows for differential analysis. For example, on the levels and types of investment in relation 
502 to the scientific areas and to differentiated subgroups of students according to their socio-

503 cultural origin or their vocational career projects. With the Bologna Declaration (1999),

504 governments in European countries advocated for higher education to value and be based on

505 the active participation of students in their skills development and learning. This perspective

506 benefits from brief and multidimensional instruments that ensure a large-scale assessment of

507 the students' levels of academic engagement as related to their behavioral, cognitive and

508 emotional aspects.

\section{Conclusions}

511 All the research hypotheses were confirmed, pointing to the validity evidence of the

512 obtained findings, something that goes in line with other previous studies (Costa et al. 2014;

513 Costa and Marôco 2017; Marôco et al. 2016). There seems to be evidence that the USEI is

514 an appropriate psychometric instrument for the academic engagement framework adopted,

515 which is multidimensional and comprised of observable behaviors, emotions and internal

516 cognitions. Thus, it can help to capitalize on the potential of academic engagement as a

517 multidimensional construct (Fredricks 2015), with a higher-order dimension, academic

518 engagement. Our findings bring clarity regarding the psychometric properties of this

519 promising instrument, which can successfully measure the three different kinds of academic

520 engagement from the most adopted theoretical framework. This is the first instrument that

521 enables Portuguese university students to do so. Due to its reduced number of items this

522 instrument can be adequate to research proposes in large scale related with academic

523 engagement, and to practical purposes at the intervention levels can allow to identify

524 dimensions where teachers and university staff can design interventions based on the 525 specificities of each scientific areas or students' subgroups. 
Future studies should address longitudinal research designs, such as longitudinal

527 measurement invariance and measurement invariance for public/private universities, with

528 students from different graduation years, something that isn't often implemented as it should

529 be, since it is a condition for making proper comparisons between different groups (Davidov

530 et al. 2014). Future studies should also look at transcultural validity of the USEI in different

531 languages, other than the European/Brazilian Portuguese for which the USEI was initially 532 developed.

533 Also, other kinds of validity evidence should be addressed, such as evidence of

534 validity based on relationships with measures of other variables like student achievement, 535 drop-out, burnout and well-being (McCoach et al. 2013). Our sample only included first-year 536 students from a Portuguese public university, and it is desirable that other and more diverse 537 scientific areas of graduation should be included, such as students from private universities 538 and different grades, and also students with another status (such as a student worker).

540 Funding This work received no grants or assistance from a funding body.

\section{Compliance with Ethical Standards}

542 Conflict of Interest On behalf of all authors, the corresponding author states that there 543 is no conflict of interest.

544 Ethical Approval All procedures performed in studies involving human participants 545 were in accordance with the ethical standards of the Institutional Ethics Research 546 Committee and with the 1964 Helsinki declaration and its later amendments or 547 comparable ethical standards. 
548 Informed Consent Informed consent was obtained from all individual participants

549 included in the study. 


\section{References}

552

553

554

555

556

557

558

559

560

561

562

563

564

565

566

567

568

569

570

571

572

573

574

575

576

577

578

579

580

581

582

583

584

585

586

587

588

589

590

591

592

593

594

595

596

Alrashidi, O., Phan, H. P., \& Ngu, B. H. (2016). Academic engagement: An overview of its definitions, dimensions, and major conceptualisations. International Education Studies, 9(12), 41-52. doi:10.5539/ies.v9n12p41

American Educational Research Association, American Psychological Association, \& National Council on Measurement in Education. (2014). Standards for Educational and Psychological Testing. Washington, DC, USA: American Psychological Association.

American Psychological Association. (1954). Technical recommendations for psychological tests and diagnostic techniques. Psychological Bulletin, 51(2), 201-238. doi:10.1037/h0053479

Antúnez, Á., Cervero, A., Solano, P., Bernardo, I., \& Carbajal, R. (2017). Engagement: A new perspective for reducing dropout through self-regulation. In J. A. GonzálezPienda, A. Bernardo, J. C. Núñez, \& C. Rodríguez (Eds.), Factors affecting academic performance (pp. 25-46). New York, NY, USA: Nova Science Publishers.

Appleton, J. J., Christenson, S. L., \& Furlong, M. J. (2008). Student engagement with school: Critical conceptual and methodological issues of the construct. Psychology in the Schools, 45(5), 369-386. doi:10.1002/pits.20303

Appleton, J. J., Christenson, S. L., Kim, D., \& Reschly, A. L. (2006). Measuring cognitive and psychological engagement: Validation of the Student Engagement Instrument. Journal of School Psychology, 44(5), 427-445. doi:10.1016/j.jsp.2006.04.002

Bakker, A. B., Schaufeli, W. B., Leiter, M. P., \& Taris, T. W. (2008). Work engagement: An emerging concept in occupational health psychology. Work \& Stress, 22(3), 187200. doi:10.1080/02678370802393649

Banta, T. W., Pike, G. R., \& Hansen, M. J. (2009). The use of engagement data in accreditation, planning, and assessment. New Directions for Institutional Research, 2009(141), 21-34. doi:10.1002/ir.284

Barkley, E. F. (2010). Student engagement techniques: A handbook for college faculty. San Francisco, CA, USA: John Wiley \& Sons.

Bernardo, A., Cervero, A., Esteban, M., Tuero, E., Casanova, J. R., \& Almeida, L. S. (2017). Freshmen program withdrawal: Types and recommendations. Frontiers in Psychology, 8, 1-11. doi:10.3389/fpsyg.2017.01544

Bollen, K. A. (1989). Structural equations with latent variables. New York, NY, USA: Wiley. doi:10.1002/9781118619179

Bologna Declaration. The European higher education area. Joint Declaration of the European Ministers of Education, June 19, Bologna. (1999). https://www.eurashe.eu/library/bologna_1999_bologna-declaration-pdf/

Bresó, E., Schaufeli, W. B., \& Salanova, M. (2011). Can a self-efficacy-based intervention decrease burnout, increase engagement, and enhance performance? A quasiexperimental study. Higher Education, 61(4), 339-355. doi:10.1007/s10734-0109334-6

Brown, T. A. (2015). Confirmatory factor analysis for applied research (2nd ed.). New York, NY, USA: The Guildford Press.

Carter, C. P., Reschly, A. L., Lovelace, M. D., Appleton, J. J., \& Thompson, D. (2012). Measuring student engagement among elementary students: Pilot of the Student Engagement Instrument- Elementary version. School Psychology Quarterly, 27(2), 
61-73. doi:10.1037/a0029229

Chapman, C., Laird, J., Ifill, N., \& KewalRamani, A. (2011). Trends in high school dropout and completion rates in the United States: 1972 - 2009 (No. compendium report 2012-006). National Center for Education Statistics. http://nces.ed.gov/pubsearch

Chen, F. F., Sousa, K. H., \& West, S. G. (2005). Teacher's corner: Testing measurement invariance of second-order factor models. Structural Equation Modeling: A Multidisciplinary Journal, 12(3), 471-492. doi:10.1207/s15328007sem1203_7

Cheung, G. W., \& Rensvold, R. B. (2002). Evaluating goodness-of-fit indexes for testing measurement invariance. Structural Equation Modeling: A Multidisciplinary Journal, 9(2), 233-255. doi:10.1207/S15328007SEM0902_5

Christensen, M. (2017). Work engagement and job crafting. In M. Christensen, P. Ø. Saksvik, \& M. Karanika-Murray (Eds.), The positive side of occupational health psychology (pp. 79-90). Cham, Switzerland: Springer. doi:10.1007/978-3-319-66781$2 \_7$

Christenson, S. L., \& Reschly, A. L. (2010). Check \& connect: Enhancing school completion through student engagement. In B. Doll, W. Pfohl, \& J. Yoon (Eds.), Handbook of youth prevention science (pp. 327-334). New York, NY, USA: Routledge.

Christenson, S. L., Reschly, A. L., \& Wylie, C. (Eds.). (2012). Handbook of research on student engagement. New York, NY, USA: Springer. doi:10.1007/978-1-4614-2018-7

Coates, H. (2005). The value of student engagement for higher education quality assurance. Quality in Higher Education, 11(1), 25-36. doi:10.1080/13538320500074915

Coetzee, M., \& Oosthuizen, R. M. (2012). Students' sense of coherence, study engagement and self-efficacy in relation to their study and employability satisfaction. Journal of Psychology in Africa, 22(3), 315-322. doi:10.1080/14330237.2012.10820536

Costa, A. R., Araújo, A. M., \& Almeida, L. S. (2014). Envolvimento académico de estudantes de engenharia: Contributos para a validação interna e externa de uma escala de avaliação. Revista Eletrónica de Psicologia, Educação e Saúde, 4(1), 142-155. http://www.revistaepsi.com

Costa, A. R., \& Marôco, J. (2017). Inventário de envolvimento académico dos estudantes do Ensino Superior (USEI). In L. S. Almeida, M. R. Simões, \& M. M. Gonçalves (Eds.), Adaptação, desenvolvimento e sucesso académico dos estudantes do ensino superior: Instrumentos de avaliação (pp. 33-44). Braga, Portugal: ADIPSIEDUC.

Crutzen, R., \& Peters, G.-J. Y. (2017). Scale quality: Alpha is an inadequate estimate and factor-analytic evidence is needed first of all. Health Psychology Review, 11(3), 242247. doi:10.1080/17437199.2015.1124240

Davidov, E., Meuleman, B., Cieciuch, J., Schmidt, P., \& Billiet, J. (2014). Measurement equivalence in cross-national research. Annual Review of Sociology, 40(1), 55-75. doi:10.1146/annurev-soc-071913-043137

Dilekmen, M. (2007). Orientation program and adaptation of university students. Psychological Reports, 101(7), 1141-1144. doi:10.2466/PR0.101.7.1141-1144

Eccles, J., \& Wang, M.-T. (2012). So what is student engagement anyway? In S. L. Christenson, A. L. Reschly, \& C. Wylie (Eds.), Handbook of research on student engagement (pp. 133-145). Boston, MA, USA: Springer. doi:10.1007/978-1-46142018-7_6

Edwards, M. C., Houts, C. R., \& Wirth, R. J. (2017). Measurement invariance, the lack thereof, and modeling change. Quality of Life Research, 1-9. doi:10.1007/s11136- 
644

017-1673-7

Elmore, G. M., \& Huebner, E. S. (2010). Adolescents' satisfaction with school experiences: Relationships with demographics, attachment relationships, and school engagement behavior. Psychology in the Schools, 47(6), 525-537. doi:10.1002/pits.20488

Finn, J. D., \& Zimmer, K. S. (2012). Student engagement: What is it? Why does it matter? In S. L. Christenson, A. L. Reschly, \& C. Wylie (Eds.), Handbook of research on student engagement (pp. 97-131). Boston, MA, USA: Springer. doi:10.1007/978-14614-2018-7_5

Finney, S. J., \& DiStefano, C. (2013). Non-normal and categorical data in structural equation modeling. In G. R. Hancock \& R. O. Mueller (Eds.), Structural equation modeling: A second course (2nd ed., pp. 439-492). Charlotte, NC, USA: Information Age Publishing.

Fredricks, J. A. (2015). Academic engagement. In J. D. Wright (Ed.), International encyclopedia of the social \& behavioral sciences (2nd ed., Vol. 1, pp. 31-36). San Diego, CA, USA: Elsevier. doi:10.1016/B978-0-08-097086-8.26085-6

Fredricks, J. A., Blumenfeld, P. C., \& Paris, A. H. (2004). School engagement: Potential of the concept, state of the evidence. Review of Educational Research, 74(1), 59-109. doi:10.3102/00346543074001059

Fredricks, J. A., Filsecker, M., \& Lawson, M. A. (2016). Student engagement, context, and adjustment: Addressing definitional, measurement, and methodological issues. Learning and Instruction, 43, 1-4. doi:10.1016/j.learninstruc.2016.02.002

Fredricks, J. A., \& McColskey, W. (2012a). The measurement of student engagement: A comparative analysis of various methods and student self-report instruments. In S. L. Christenson, A. L. Reschly, \& C. Wylie (Eds.), Handbook of research on student engagement (pp. 763-782). Boston, MA, USA: Springer. doi:10.1007/978-1-46142018-7_37

Fredricks, J. A., \& McColskey, W. (2012b). The measurement of student engagement: A comparative analysis of various methods and student self-report instruments. In S. L. Christenson, A. L. Reschly, \& C. Wylie (Eds.), Handbook of research on student engagement (pp. 763-782). Boston, MA, USA: Springer. doi:10.1007/978-1-46142018-7_37

Fredricks, J. A., McColskey, W., Meli, J., Mordica, J., Montrosse, B., \& Mooney, K. (2011). Measuring student engagement in upper elementary through high school: A description of 21 instruments (No. Issues \& Answers report, REL 2011-No. 098). Washington, DC, USA: Department of Education, Institute of Education Sciences, National Center for Education Evaluation and Regional Assistance, Regional Educational Laboratory Southeast. http://ies.ed.gov/ncee/edlabs

Gilardi, S., \& Guglielmetti, C. (2011). University life of non-traditional students: Engagement styles and impact on attrition engagement styles and impact on attrition. The Journal of Higher Education, 82(1), 33-53. doi:10.1080/00221546.2011.11779084

Green, S. B., \& Yang, Y. (2009). Reliability of summed item scores using structural equation modeling: An alternative to coefficient alpha. Psychometrika, 74(1), 155167. doi:10.1007/s11336-008-9099-3

Handelsman, M. M., Briggs, W. L., Sullivan, N., \& Towler, A. (2005). A measure of college student course engagement. The Journal of Educational Research, 98(3), 184192. doi:10.3200/JOER.98.3.184-192 
691

692

693

694

695

696

697

698

699

700

701

702

703

704

705

706

707

708

709

710

711

712

713

714

715

716

717

718

719

720

721

722

723

724

725

726

727

728

729

730

731

732

733

734

735

736

737
Henseler, J., Ringle, C. M., \& Sarstedt, M. (2015). A new criterion for assessing discriminant validity in variance-based structural equation modeling. Journal of the Academy of Marketing Science, 43(1), 115-135. doi:10.1007/s11747-014-0403-8

Hirschi, A. (2012). Callings and work engagement: Moderated mediation model of work meaningfulness, occupational identity, and occupational self-efficacy. Journal of Counseling Psychology, 59(3), 479-485. doi:10.1037/a0028949

Hodson, P., \& Thomas, H. (2003). Quality assurance in Higher Education: Fit for the new millennium or simply year 2000 compliant? Higher Education, 45(3), 375-387. doi:10.1023/A:1022665818216

Hu, L., \& Bentler, P. M. (1999). Cutoff criteria for fit indexes in covariance structure analysis: Conventional criteria versus new alternatives. Structural Equation Modeling: A Multidisciplinary Journal, 6(1), 1-55. doi:10.1080/10705519909540118

Jorgensen, T. D., Pornprasertmanit, S., Schoemann, A. M., \& Rosseel, Y. (2018). semTools: Useful tools for structural equation modeling ( $\mathrm{R}$ package version 0.415.930) [Computer software]. https://cran.r-project.org/package=semTools

Kahu, E. R. (2013). Framing student engagement in higher education. Studies in Higher Education, 38(5), 758-773. doi:10.1080/03075079.2011.598505

Kaplan, R. M., \& Saccuzzo, D. P. (2013). Psychological testing: Principles, applications \& issues (8th ed.). Belmont, CA, USA: Wadsworth.

Kelley, K., \& Pornprasertmanit, S. (2016). Confidence intervals for population reliability coefficients: Evaluation of methods, recommendations, and software for composite measures. Psychological Methods, 21(1), 69-92. doi:10.1037/a0040086

Kember, D., \& Leung, D. Y. P. (2009). Development of a questionnaire for assessing students' perceptions of the teaching and learning environment and its use in quality assurance. Learning Environments Research, 12(1), 15-29. doi:10.1007/s10984-0089050-7

Klem, A. M., \& Connell, J. P. (2004). Relationships matter: Linking teacher support to student engagement and achievement. Journal of School Health, 74(7), 262-273. doi:10.1111/j.1746-1561.2004.tb08283.x

Kline, R. B. (2016). Principles and practice of structural equation modeling (4th ed.). New York, NY, USA: The Guildford Press.

Kong, Q., Wong, N.-Y., \& Lam, C.-C. (2003). Student engagement in mathematics: Development of instrument and validation of construct. Mathematics Education Research Journal, 15(1), 4-21. doi:10.1007/BF03217366

Krause, K.-L., \& Coates, H. (2008). Students' engagement in first-year university. Assessment \& Evaluation in Higher Education, 33(5), 493-505. doi:10.1080/02602930701698892

Kuh, G. D. (2001). Assessing what really matters to student learning: Inside The National Survey of Student Engagement. Change: The Magazine of Higher Learning, 33(3), 10-17. doi:10.1080/00091380109601795

Kuh, G. D. (2005). Student engagement in the first year of college. In M. L. Upcraft, J. N. Gardner, \& B. O. Barefoot (Eds.), Challenging and supporting the first-year student: A handbook for improving the first year of college (pp. 86-107). San Francisco, CA, USA: Jossey-Bass. http://www.ncsu.edu/uap/transition_taskforce/documents/documents/ReferenceMateri alPart3.pdf

Kuh, G. D. (2009). The National Survey of Student Engagement: Conceptual and empirical 
738

foundations. New Directions for Institutional Research, 2009(141), 5-20. doi:10.1002/ir.283

Lee, J.-S. (2014). The relationship between student engagement and academic performance: Is it a myth or reality? The Journal of Educational Research, 107(3), 177-185. doi:10.1080/00220671.2013.807491

Lin, S.-H., \& Huang, Y.-C. (2018). Assessing college student engagement: Development and validation of the student course engagement scale. Journal of Psychoeducational Assessment, 36(7), 694-708. doi:10.1177/0734282917697618

Mandernach, B. J. (2015). Assessment of student engagement in higher education: A synthesis of literature and assessment tools. International Journal of Learning, Teaching and Educational Research, 12(2), 1-14. doi:10.1073/pnas.94.17.9499

Mardia, K. V. (1970). Measures of multivariate skewness and kurtosis with applications. Biometrika, 57(3), 519-530. doi:10.1093/biomet/57.3.519

Marôco, J. (2014). Análise de equações estruturais: Fundamentos teóricos, software \& aplicações (2nd ed.). Pêro Pinheiro, Portugal: ReportNumber.

Maroco, J., Maroco, A. L., \& Campos, J. A. D. B. (2014). Student's Academic Efficacy or Inefficacy? An Example on How to Evaluate the Psychometric Properties of a Measuring Instrument and Evaluate the Effects of Item Wording. Open Journal of Statistics, 04(06), 484-493. doi:10.4236/ojs.2014.46046

Marôco, J., Marôco, A. L., Campos, J. A. D. B., \& Fredricks, J. A. (2016). University student's engagement: Development of the University Student Engagement Inventory (USEI). Psicologia: Reflexão e Crítica, 29(21), 1-12. doi:10.1186/s41155-016-0042-8

Marsh, H. W., Lüdtke, O., Muthén, B. O., Asparouhov, T., Morin, A. J. S., Trautwein, U., \& Nagengast, B. (2010). A new look at the big five factor structure through exploratory structural equation modeling. Psychological assessment, 22(3), 471-491. doi:10.1037/a0019227

McCoach, D. B., Gable, R. K., \& Madura, J. P. (Eds.). (2013). Evidence based on relations to other variables: Bolstering the empirical validity arguments for constructs. In Instrument development in the affective domain (3rd ed., pp. 209-248). New York, NY, USA: Springer. doi:10.1007/978-1-4614-7135-6_6

McDonald, R. P. (1999). Test theory: A unified treatment. Mahwah, NJ, USA: Routledge. doi:10.4324/9781410601087

Millsap, R. E., \& Yun-Tein, J. (2004). Assessing factorial invariance in ordered-categorical measures. Multivariate Behavioral Research, 39(3), 479-515. doi:10.1207/S15327906MBR3903_4

National Research Council, \& Institute of Medicine. (2004). Engaging schools: Fostering school students' motivation to learn. Washington, DC, USA: National Academies Press. doi:10.17226/10421

Pascarella, E. T., \& Terenzini, P. T. (2005). How college affects students: A third decade of research (Vol. 2). San Francisco, CA, USA: Jossey-Bass.

R Core Team. (2018). R: A language and environment for statistical computing (version 3.5.1) [Computer software]. Vienna, Austria: R Foundation for Statistical Computing. https://www.r-project.org/

Raykov, T. (2001). Estimation of congeneric scale reliability using covariance structure analysis with nonlinear constraints. The British Journal of Mathematical and Statistical Psychology, 54, 315-323. doi:10.1348/000711001159582

Reis, D., Xanthopoulou, D., \& Tsaousis, I. (2015). Measuring job and academic burnout 
with the Oldenburg Burnout Inventory (OLBI): Factorial invariance across samples and countries. Burnout Research, 2(1), 8-18. doi:10.1016/j.burn.2014.11.001

Reschly, A. L., \& Christenson, S. L. (2012a). Jingle, jangle, and conceptual haziness: Evolution and future directions of the engagement construct. In S. L. Christenson, A. L. Reschly, \& C. Wylie (Eds.), Handbook of research on student engagement (pp. 319). Boston, MA, USA: Springer. doi:10.1007/978-1-4614-2018-7_1

Reschly, A. L., \& Christenson, S. L. (2012b). Jingle, jangle, and conceptual haziness: Evolution and future directions of the engagement construct. In S. L. Christenson, A. L. Reschly, \& C. Wylie (Eds.), Handbook of research on student engagement (pp. 319). Boston, MA, USA: Springer. doi:10.1007/978-1-4614-2018-7_1

Revelle, W. (2017). psych: Procedures for psychological, psychometric, and personality research (R package version 1.7.8) [Computer software]. Evanston, IL: Northwestern University. https://cran.r-project.org/package=psych

Revelle, W., \& Zinbarg, R. E. (2009). Coefficients alpha, beta, omega, and the glb: Comments on sijtsma. Psychometrika, 74(1), 145-154. doi:10.1007/s11336-008-9102$\mathrm{Z}$

Rios, J., \& Wells, C. (2014). Validity evidence based on internal structure. Psicothema, 26(1), 108-16. doi:10.7334/psicothema2013.260

Rodriguez, A., Reise, S. P., \& Haviland, M. G. (2016). Applying bifactor statistical indices in the evaluation of psychological measures. Journal of Personality Assessment, 98(3), 223-237. doi:10.1080/00223891.2015.1089249

Rosseel, Y. (2012). lavaan: An R package for structural equation modeling. Journal of Statistical Software, 48(2), 1-21. http://www.jstatsoft.org/v48/i02/paper

RStudio Team. (2017). RStudio: Integrated development for R (version 1.1.345) [Computer software]. Boston, MA, USA: RStudio, Inc. http://www.rstudio.com/

Rubia, E. A. de la, Zhu, H., Ellis, S., Waring, E., \& Quinn, M. (2017). skimr: skimr (R package version 0.9000) [Computer software].

Satorra, A., \& Bentler, P. M. (2001). A scaled difference chi-square test statistic for moment structure analysis. Psychometrika, 66(4), 507-514. doi:10.1007/BF02296192

Schaufeli, W. B., \& Bakker, A. B. (2010). Defining and measuring work engagement: Bringing clarity to the concept. In A. B. Bakker \& M. P. Leiter (Eds.), Work engagement: A handbook of essential theory and research (pp. 10-24). New York, NY: Psychology Press. http://psycnet.apa.org/psycinfo/2010-06187-002

Schaufeli, W. B., Martinez, I. M., Marques-Pinto, A., Salanova, M., \& Bakker, A. B. (2002). Burnout and engagement in university students: A cross-national study. Journal of Cross-Cultural Psychology, 33(5), 464-481. doi:10.1177/0022022102033005003

Schaufeli, W. B., Martinez, I. M., Marques Pinto, A., Salanova, M., \& Bakker, A. B. (2002). Burnout and engagement in university students: A cross-national study. Journal of Cross-Cultural Psychology, 33(5), 464-481. doi:10.1177/0022022102033005003

semTools Contributors. (2016). semTools: Useful tools for structural equation modeling (R package version 0.4-14) [Computer software]. https://cran.rproject.org/package $=$ semTools

Senior, C., \& Howard, C. (2015). Editorial: The state of the art in student engagement. Frontiers in Psychology, 6, 1-2. doi:10.3389/fpsyg.2015.00355 
832

833

834

835

836

837

838

839

840

841

842

843

844

845

846

847

848

849

850

851

852

853

854

855

856

857

858

859

860

861

862

863

864

865

866

867

868

869

870

871

872

873

874

875

876

877
Education, 45(1), 111-123. doi:10.1111/j.1467-9752.2010.00782.x

Sinval, J., Marques-Pinto, A., Queirós, C., \& Marôco, J. (2018). Work engagement among rescue workers: Psychometric properties of the Portuguese UWES. Frontiers in Psychology, 8. doi:10.3389/fpsyg.2017.02229

Sireci, S. G., \& Padilla, J.-L. (2014). Validating assessments: Introduction to the special section. Psicothema, 26(1), 97-99. doi:10.7334/psicothema2013.255

Streiner, D. L. (2003). Starting at the beginning: An introduction to coefficient alpha and internal consistency. Journal of Personality Assessment, 80(1), 99-103. doi:10.1207/S15327752JPA8001_18

van de Schoot, R., Lugtig, P., \& Hox, J. J. (2012). A checklist for testing measurement invariance. European Journal of Developmental Psychology, 9(4), 486-492. doi:10.1080/17405629.2012.686740

van de Schoot, R., Schmidt, P., \& De Beuckelaer, A. (Eds.). (2015). Measurement invariance. Lausanne, Switzerland: Frontiers Media. doi:10.3389/978-2-88919-650-0

Vasalampi, K., Salmela-Aro, K., \& Nurmi, J.-E. (2009). Adolescents' self-concordance, school engagement, and burnout predict their educational trajectories. European Psychologist, 14(4), 332-341. doi:10.1027/1016-9040.14.4.332

Wierstra, R. F. A., Kanselaar, G., van der Linden, J. L., Lodewijks, H. G. L. C., \& Vermunt, J. D. (2003). The impact of the university context on European students' learning approaches and learning environment preferences. Higher Education, 45(4), 503-523. doi:10.1023/A:1023981025796

Wigfield, A., Guthrie, J. T., Perencevich, K. C., Taboada, A., Klauda, S. L., McRae, A., \& Barbosa, P. (2008). Role of reading engagement in mediating effects of reading comprehension instruction on reading outcomes. Psychology in the Schools, 45(5), 432-445. doi:10.1002/pits.20307

Wolf-Wendel, L., Ward, K., \& Kinzie, J. (2009). A tangled web of terms: The overlap and unique contribution of involvement, engagement, and integration to understanding college student success. Journal of College Student Development, 50(4), 407-428. doi:10.1353/csd.0.0077

Wonglorsaichon, B., Wongwanich, S., \& Wiratchai, N. (2014). The influence of students school engagement on learning achievement: A structural equation modeling analysis. Procedia - Social and Behavioral Sciences, 116, 1748-1755. doi:10.1016/j.sbspro.2014.01.467

Zinbarg, R. E., Revelle, W., \& Yovel, I. (2007). Estimating wh for structures containing two group factors: Perils and prospects. Applied Psychological Measurement, 31(2), 135-157. doi:10.1177/0146621606291558

Zinbarg, R. E., Revelle, W., Yovel, I., \& Li, W. (2005). Cronbach's $\alpha$, Revelle's $\beta$, and Mcdonald's $\omega \mathrm{H}$ : Their relations with each other and two alternative conceptualizations of reliability. Psychometrika, 70(1), 123-133. doi:10.1007/s11336-003-0974-7

Zumbo, B. D., Gadermann, A. M., \& Zeisser, C. (2007). Ordinal versions of coefficients Alpha and Theta for likert rating scales. Journal of Modern Applied Statistical Methods, 6(1), 21-29. http://digitalcommons.wayne.edu/jmasm\%5Cnhttp://digitalcommons.wayne.edu/jmas $\mathrm{m} / \mathrm{vol} / \mathrm{iss} 1 / 4$ 
Table 1. Distributional properties of USEI's items

\begin{tabular}{ccccccccc}
\hline item & missing & $N$ & $M$ & $S D$ & $\min$ & $\max$ & histogram \\
\hline eng1 & 0 & 908 & 3.96 & 0.62 & 1 & 5 & \\
eng2 & 2 & 908 & 4.62 & 0.57 & 1 & 5 & \\
eng3 & 2 & 908 & 4.20 & 0.79 & 1 & 5 & \\
eng4 & 1 & 908 & 3.35 & 0.91 & 1 & 5 & \\
eng5 & 7 & 908 & 4.36 & 0.76 & 1 & 5 & \\
eng6 & 5 & 908 & 3.88 & 1.01 & 1 & 5 & \\
eng7 & 1 & 908 & 3.81 & 0.75 & 1 & 5 & \\
eng8 & 3 & 908 & 4.14 & 0.74 & 1 & 5 & \\
eng9 & 4 & 908 & 3.91 & 0.79 & 1 & 5 & \\
eng10 & 11 & 908 & 3.69 & 0.77 & 1 & 5 & \\
eng11 & 2 & 908 & 3.84 & 0.90 & 1 & 5 & 5 \\
eng12 & 1 & 908 & 3.57 & 0.92 & 1 & 5 & 5 \\
eng13 & 2 & 908 & 4.07 & 0.84 & 1 & 5 & 5 \\
eng14 & 1 & 908 & 3.93 & 0.71 & 1 & 5 & \\
eng15 & 2 & 908 & 4.07 & 0.71 & 1 & 5 & \\
\hline
\end{tabular}

Note. $\mathrm{R}$ - reversed. 
882

Table 2. Internal consistency of USEI dimensions for the Total Sample

\begin{tabular}{llll}
\hline USEI's dimensions & $\alpha_{\text {ordinal }}$ & $\omega_{\text {ordinal }}$ & $C R$ \\
\hline $\mathrm{BE}$ & .69 & .63 & .70 \\
\hline $\mathrm{EE}$ & .83 & .78 & .85 \\
\hline $\mathrm{CE}$ & .80 & .75 & .82 \\
\hline Total & .87 & .85 & - \\
\hline
\end{tabular}

883 
Table 3. USEI's models comparisons for gender

\begin{tabular}{|c|c|c|c|c|c|c|}
\hline Model invariance & $\chi^{2}$ & df & $\chi 2 / \mathrm{df}$ & CFI scaled & $\Delta \chi 2$ & $\triangle C F I$ scaled \\
\hline Configural (factor structure) & 336.29 & 174 & 1.93 & .968 & - & - \\
\hline First-order loadings invariance & 353.66 & 186 & 1.90 & .969 & $6.94^{n s}$ & .001 \\
\hline Second-order loadings invariance & 353.88 & 188 & 1.88 & .970 & $0.12^{\text {ns }}$ & .001 \\
\hline Thresholds of measured variables & 460.47 & 230 & 2.00 & .964 & $57.61^{* * *}$ & .006 \\
\hline $\begin{array}{l}\text { Intercepts of first-order factors in- } \\
\text { variance }\end{array}$ & 499.33 & 233 & 2.14 & .963 & $5.44^{*}$ & .001 \\
\hline $\begin{array}{l}\text { Disturbances of first-order factors } \\
\text { invariance }\end{array}$ & 502.59 & 235 & 2.14 & .963 & $1.40^{n s}$ & .000 \\
\hline $\begin{array}{l}\text { Residual variances of observed vari- } \\
\text { ables invariance }\end{array}$ & 578.33 & 250 & 2.31 & .959 & $37.90^{* * *}$ & .004 \\
\hline
\end{tabular}

Notes. ${ }^{n s} p>.05 ;{ }^{*} p<.05 ;{ }^{* * *} p<.001$ 
Table 4. USEI's models comparisons for scientific area of graduation

\begin{tabular}{|c|c|c|c|c|c|c|}
\hline Model invariance & $\chi^{2}$ & df & $\chi^{2 / \mathrm{df}}$ & CFI scaled & $\Delta \chi 2$ & $\triangle C F I$ scaled \\
\hline Configural (factor structure) & 539.91 & 262 & 2.06 & .959 & - & - \\
\hline First-order loadings invariance & 497.07 & 285 & 1.74 & .969 & $13.14^{n s}$ & .010 \\
\hline Second-order loadings invariance & 579.04 & 290 & 2.00 & .962 & $25.70^{* * *}$ & .007 \\
\hline Thresholds of measured variables & 684.93 & 373 & 1.84 & .963 & $28.70^{n s}$ & .001 \\
\hline $\begin{array}{l}\text { Intercepts of first-order factors in- } \\
\text { variance }\end{array}$ & 736.91 & 379 & 1.94 & .962 & $5.67^{n s}$ & .001 \\
\hline $\begin{array}{l}\text { Disturbances of first-order factors } \\
\text { invariance }\end{array}$ & 747.34 & 384 & 1.95 & .963 & $2.17^{n s}$ & .001 \\
\hline $\begin{array}{l}\text { Residual variances of observed vari- } \\
\text { ables invariance }\end{array}$ & 841.20 & 414 & 2.03 & .961 & $28.32^{* *}$ & .002 \\
\hline
\end{tabular}

Notes. ${ }^{n s} p>.05 ;{ }^{* *} p<.01 ;{ }^{* * *} p<.001$ 


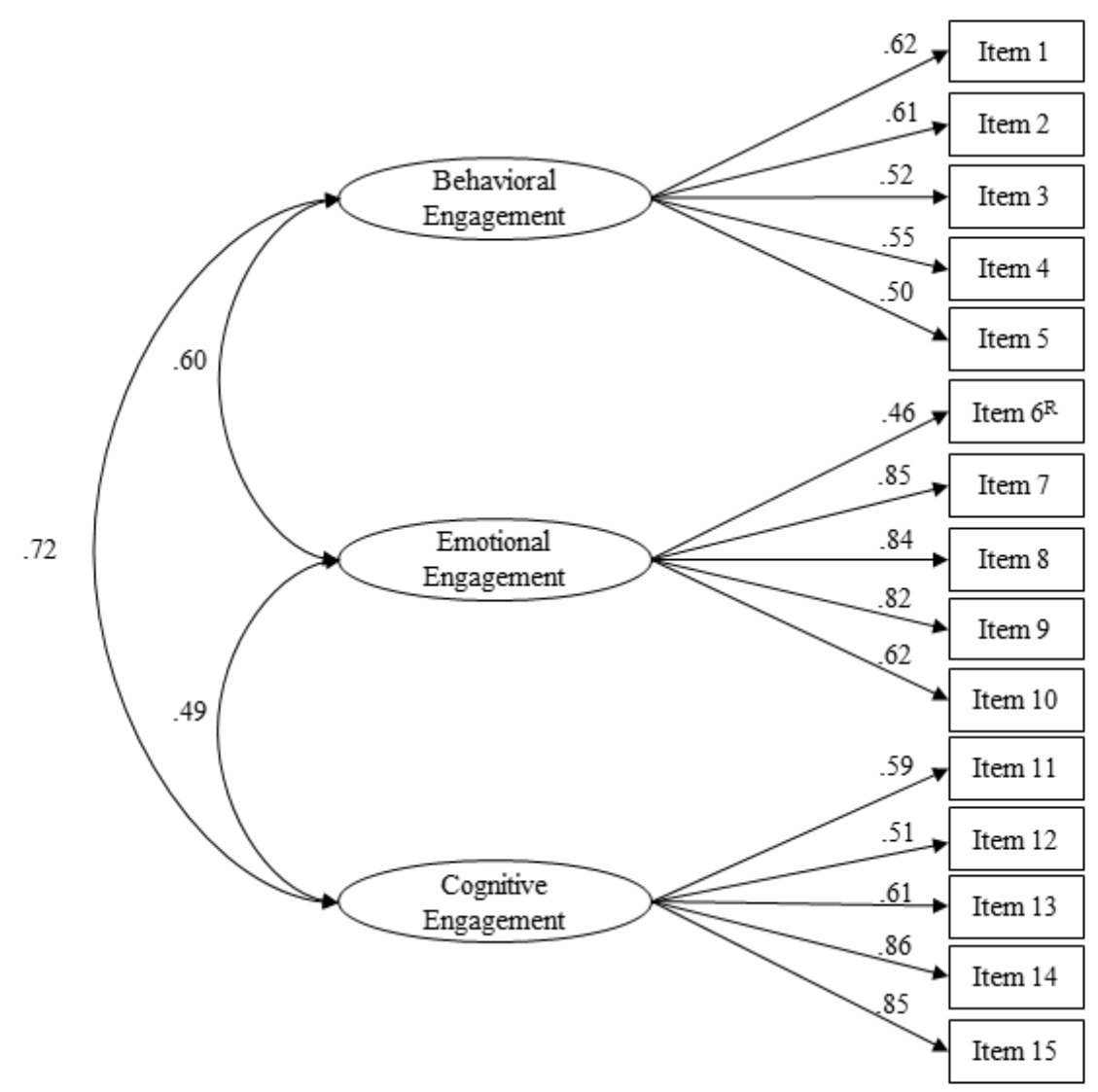




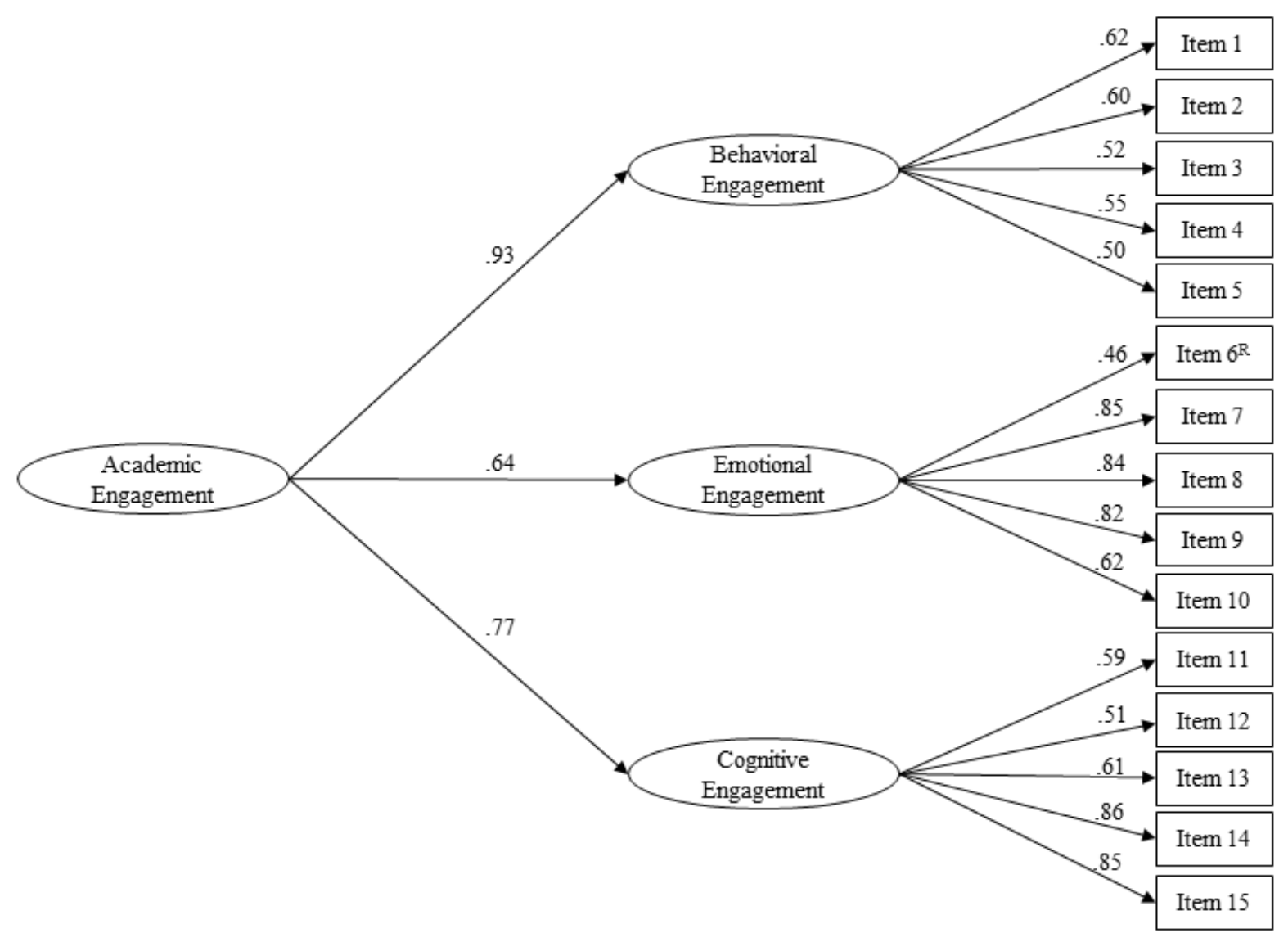

